\title{
Spontaneous corneal perforation in a patient with lamellar ichthyosis and dry eye
}

This article was published in the following Dove Press journal:

Clinical Ophthalmology

3 November 2009

Number of times this article has been viewed

\section{Burak Turgut' \\ Orhan Aydemir' \\ Murat Kaya' \\ Peykan Türkçüoğlu² \\ Tamer Demir ${ }^{\prime}$ \\ Ülkü Çeliker'}

'Fırat University School of Medicine, Department of Ophthalmology,

Elazığ, Turkey; ${ }^{2}$ Inonu University

School of Medicine, Department of

Ophthalmology, Malatya, Turkey
Correspondence: Burak Turgut Firat University School of Medicine, Department of Ophthalmology, Elazı̆g, Turkey

Tel +90 4242333555

Fax +904242388096

Email drburakturgut@gmail.com
Abstract: We report spontaneous corneal perforation in a patient with lamellar ichthyosis. The patient presented with complaints of pain, redness, diminished vision, and discharge in her right eye for 15 days. Visual acuities were light perception in the right and 20/400 in the left eye. Cicatricial ectropion in both lower eyelids and $2 \mathrm{~mm}$ perforation site in the center of the right cornea were observed. Lamellar ichthyosis was suspected because of scaling and excessive dryness of entire body skin and was confirmed by skin biopsy. Amniotic membrane transplantation and transient tarsorraphy was performed and systemic anti-ichthyosis therapy was started. The follow-up visits were not possible because of patient inconsistency. In patients with cicatricial ectropion secondary to ichthyosis, corneal health should be closely monitored because of the perforation risk.

Keywords: lamellar ichthyosis, cornea, spontaneous perforation

\section{Introduction}

A rare autosomal recessive skin disorder, Lamellar ichthyosis manifests at birth often with collodion membrane and large thick scales all over the body except on the mucous membranes and the lips. Cicatricial ectropion is the most common eyelid abnormality, which is assumed to lead to corneal exposure and ulceration. ${ }^{1}$ We report a case of corneal perforation in a patient with lamellar ichthyosis.

\section{Case history}

A 67-year-old woman presented to our clinic with complaints of pain, redness, diminished vision, and discharge in her right eye for 15 days. Visual acuities were light perception in the right and 20/400 in the left eye. Scales, mucoid discharge over eyelid skin, cicatricial ectropion in lower eyelids, conjunctival dryness, and nuclear cataract were noticed in both eyes. In the center of right cornea, a $2 \mathrm{~mm}$ perforation site that was Siedel test-positive caused shallowing of the anterior chamber. The patient did not report any ocular trauma. On general examination, scaling and excessive dryness of entire body skin was noticed. No other family members had a significant medical history except her brother who was died because of an undiagnosed skin disorder when he was twenty. On the basis of family history and examination findings (Figures 1-3), a diagnosis of lamellar ichthyosis was suspected and confirmed by skin biopsy. The skin biopsy revealed hyperkeratosis and epidermal thickening consistent with lamellar ichthyosis. Amniotic membrane transplantation and transient tarsorraphy was performed and systemic antiichthyosis therapy including vitamin A was started. The follow-up visits were not possible because of patient inconsistency. However, when we reviewed the hospital records of the 


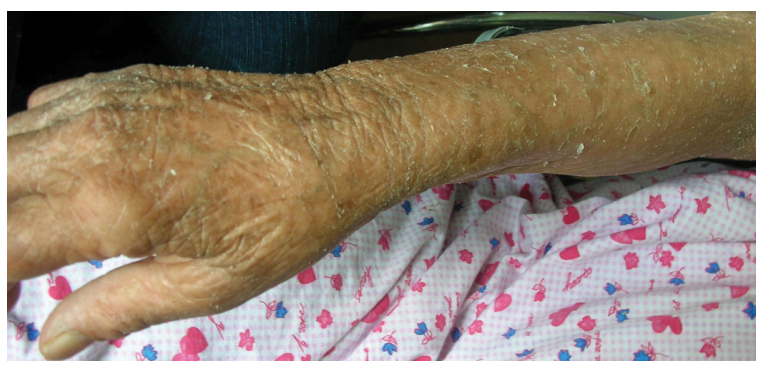

Figure I The color photograph shows the scaling and the dryness on the skin of arm.

patient we found that she was deceased due to septic shock five months after presentation to our clinic.

\section{Discussion}

Ichthyosis is a skin disorder characterized by excessive dryness of skin and increased formation of epidermal scales. There are four types of disease including ichthyosis vulgaris, sex-linked recessive, lamellar ichthyosis, and epidermolytic hyperkeratosis. The rarest form is lamellar ichthyosis, which has autosomal recessive inheritance and is due to a defect on chromosome $14 \mathrm{q} 11$ encoding transglutaminase-1 (TG). ${ }^{2}$ The association between ichthyosis and cicatricial ectropion, which is the most common eyelid malposition, was first reported in $1834 .{ }^{3}$ secondary to chronic exposure, corneal ulceration and perforation may occur in these patients. ${ }^{4} \mathrm{Cruz}$ and colleagues postulated that corneal damage is not directly linked to lower ectropion. Apart from ectropion, the other factors causing corneal damage are madarosis, conjunctivitis, eyelash retraction, and lagophthalmus. ${ }^{1}$ In patients with chronic corneal involvement, preservative-free artificial tears, petroleumointment, bandage contact lenses diminish symptoms and

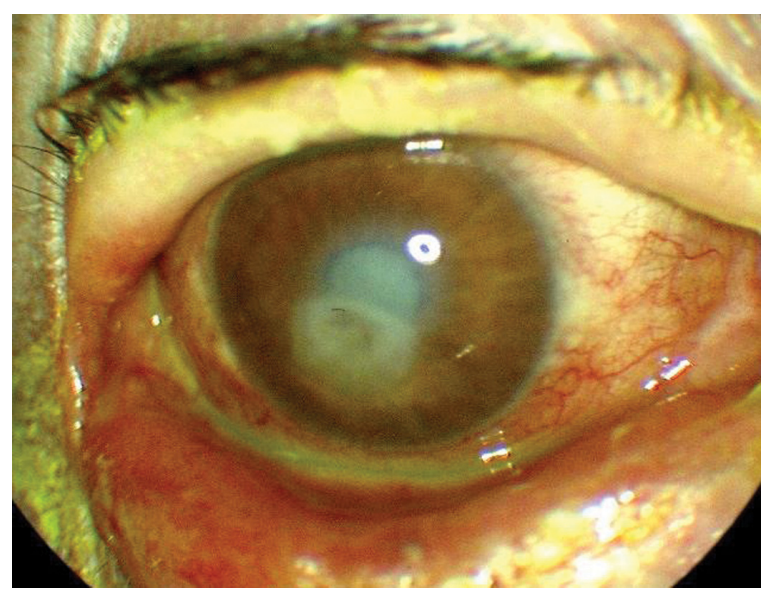

Figure $\mathbf{2}$ The color photograph shows the corneal perforation, cataractous lens, the lower ectropion, shallow anterior chamber, and conjunctival congestion in the right eye.

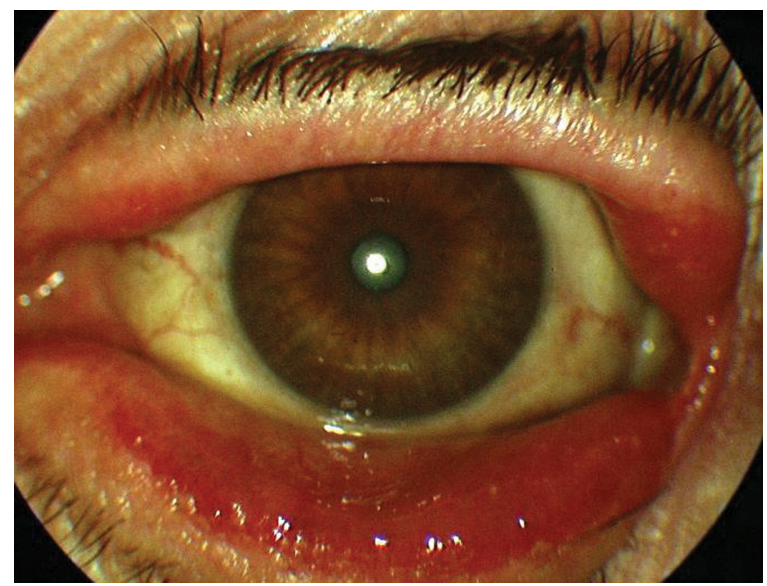

Figure 3 The color photograph shows cataractous lens and the lower ectropion in the left eye.

ease epithelial healing. In the therapy of persistent corneal epithelial defect, amniotic membrane transplantation and tarsorraphy may promote epithelial wound healing. For diffuse limbal stem cell deficiency, combined keratoplasty and limbal stem cell transplantation and long-term systemic immunosuppression may be necessary, although the success rate has been poor. Full-thickness skin grafting may be used to repair cicatricial ectropion. ${ }^{1}$ Our patient underwent a combined procedure including amniotic membrane transplantation and tarsorraphy for the corneal perforation. Because of patient inconsistency, we could not document our intervention results and the progression of disease in the other eye.

To our knowledge and an Internet search, there is only one case that reports corneal perforation in ichthyosis, which was an epidermolytic hyperkeratosis type. ${ }^{4}$ Our case is the first corneal perforation that was reported in a patient with lamellar ichthyosis. Cicatricial ectropion, a poor prognosis indicator for corneal health, can result in corneal perforation in ichthyosis. In patients with cicatricial ectropion secondary to ichthyosis, corneal health should be closely monitored because of the perforation risk.

\section{Acknowledgments}

This case has been presented in a poster at the 9th Congress of the International Society of Dacryology and Dry Eye, 2008. The authors report no conflicts of interest in this work. BT and MK conducted the study. All authors were involved in the collection of data, typing and editing of the manuscript, and preparation, review, and approval of the manuscript. All authors read and approved the final manuscript. 


\section{References}

1. Cruz AA, Menezes FA, Chaves R, Pinto Coelho R, Velasco EF, Kikuta H. Eyelid abnormalities in lamellar ichthyoses. Ophthalmology. 2000;107:1895-1898.

2. Esposito G, Tadini G, Paparo F, et al. Transglutaminase 1 deficiency and corneocyte collapse: an indication for targeted molecular screening in autosomal recessive congenital ichthyosis. $\mathrm{Br} J$ Dermatol. 2007;157:808-810.

3. Jay B, Blach RK, Wells RS. Ocular manifestations of ichthyosis. Br J Ophthalmol. 1968;52:217-226.

4. Eltutar K, Karadede S, Atlihan F, Ozler S. Ectropion and bilateral corneal perforation in a case of congenital ichthyosiform erythroderma. Clinical and histopathologic review. Ophtalmologie. 1988;2:253-254.

Clinical Ophthalmology

\section{Publish your work in this journal}

Clinical Ophthalmology is an international, peer-reviewed journal covering all subspecialties within ophthalmology. Key topics include: Optometry; Visual science; Pharmacology and drug therapy in eye diseases; Basic Sciences; Primary and Secondary eye care; Patient Safety and Quality of Care Improvements. This journal is indexed on

PubMed Central and CAS, and is the official journal of The Society of Clinical Ophthalmology (SCO). The manuscript management system is completely online and includes a very quick and fair peer-review system, which is all easy to use. Visit http://www.dovepress.com/ testimonials.php to read real quotes from published authors. 